\title{
Erratum
}

On page 32 of the paper starting on page 29 of volume 22 there were unfortunately several errors.

Curr Genet (1992) 22: 29-35

\section{Structure of the Cochliobolus heterostrophus glyceraldehyde-3-phosphate dehydrogenase gene}

\section{S. L. Van Wert* and O.C. Yoder}

Department of Plant Pathology, Cornell University, Ithaca, NY 14853, USA

Received August 26/December 20, 1991

The DNA sequence shown in Fig. 4 should be changed as indicated below:

Nucleotide Position

After bp 1127

After bp 1415

After bp 1625

Bp 1736-1738

After bp 1783

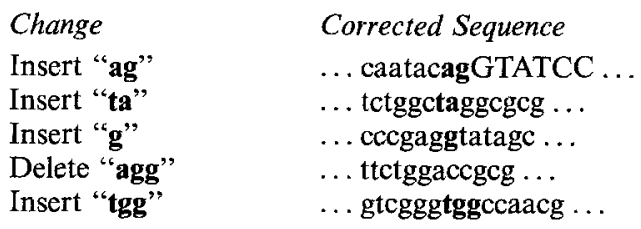

Change

Insert "ag"

Insert "ta"

Insert "g"

Delete "agg"

Insert "tgg"

Corrected Sequence

... caatacagGTATCC ...

... tctggctaggcgcg ...

... cecgaggtatagc ...

...ttctggaccgcg ...

... gtcgggtggccaacg . .

The sequence filed under Accession Number X63516 in the EMBL Data Library is correct. 